\title{
Call for biohazard legislation
}

In this article Brian J. Ford argues that the law does not concern itself sufficiently with the various hazards that can arise when microorganisms are mishandled and suggests areas in which legislation should be introduced.

LEGAL restraints and regulations are the bane of research workers in many spheres. All of us must have felt some kind of annoyance at the filling in of forms or the signing of registers that have the aura of state bureaucracy, but the justification lies in the resulting safety of research. If that is the case, it is odd that legislation covering the handling and use of microorganisms and viruses that are pathogenic to mankind is virtually nonexistent.

At the moment moves are afoot in Britain to make hepatitis a recognised industrial disease amongst hospital and laboratory staff, and there is in the United States a call for a moratorium on microbial genetic manipulation. Such piecemeal short term measures could be superseded by the greater controls of a generally accepted legal framework of safety.

In other fields of scientific endeavour there are laws that regularise the use of potentially dangerous materials. Strict controls govern the use and distribution of radioactive substances, even those of the lowest potency used in student demonstrations. Toxic chemicals are subject to a range of long standing controls including the pharmacy and poisons legislation, the poisons rules and the legal restraints on dangerous drugs. In the First Schedule of poisons appear compounds great and small, from TEPP to 2-methoxycarbonyl-1methylvinyl-diethyl phosphate; yet there is no reference to the bacterial toxins which are considerably more dangerous and also, in many respects, easier to produce.

In the regulations gaverning the security of the experimental animal appear rats, mice, rabbits; even dogs and cats. There is no mention, however, of pathogens. In the world of agriculture there are restrictions on the handling of some plant pathogens of economic significance and on the culture of viruses such as foot-and-mouth, though limitations on human pathogens are absent.

In philosophical terms the greatest hazard posed by the lack of controls over pathogens is their infectivity: poisons do not replicate. A technician who takes home an isotope may damage himself as a result, whereas a mishandled culture of virulent microorganisms could expose entire communities to widespread hazard. Yet isotopes are kept under lock and key. It is a culture of pathogenic microorganisms that needs no such safeguard in the eyes of the law.

Since I first published an outline of proposals for biohazard legislation (New Law Journal, 121 (5511), 823-824; 1971) there have been several examples of the misuse or abuse of cultures pathogenic to mankind. That paper referred to the virus of smallpox (variola) and the occasional accidents that occur when unsupervised or inexperienced staff come into contact with pathogens. Last year's outbreak in the London area is a tragic illustration of the hazard.

Children have recently been found playing with discarded culture vessels in the Midlands; and others were found to have obtained contaminated syringes casually discarded by a pharmaceutical concern in Kent. Occasionally cultures are wilfully misused. In the United States it has been reported that an underground group planned to immunise themselves against the effects of bacteria that were then to be introduced into the public water supply, and in Australia a culture of a meningitis virus was stolen (in its incubator) from a research laboratory.

Examples are known where disease has resulted from the use of unplugged mouth pipettes. A recent example in Britain involved a supposedly nonpathogenic bacterium ingested when

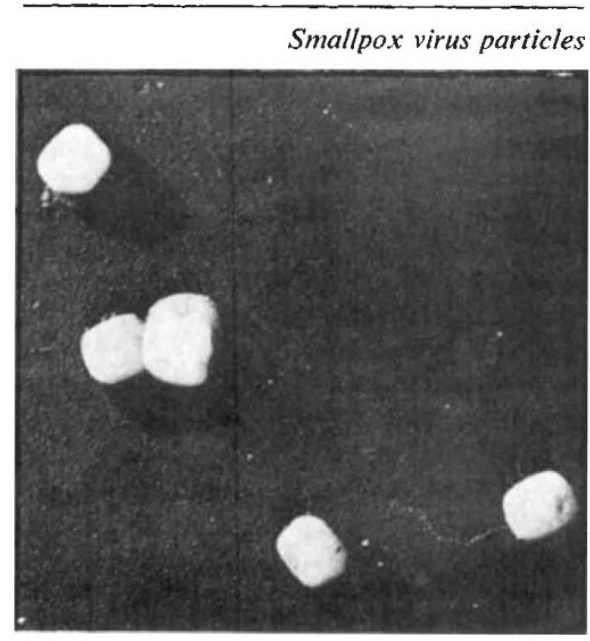

the tip of a pipette under suction was momentarily withdrawn from a thin agar culture. Elsewhere an assistant handling positive sera from syphilitics made a similar error, but did not develop the disease. I have seen a technician attempt to open a phial of polyvalent poliovirus, believing the glass to be scored. It was not, and the neck fractured and lacerated his finger.

It had not been ascertained whether he was immune to polio before commencing his work with the viruses. A similar case concerned a girl technician who saw her doctor with a sore throat, contracted shortly after she began to work with diphtheria. No check had been made on her immunological status and following representations made by the doctor to the college department the entire research team was immunised as a precaution. At a university zoology department, to cite another example, staff set up a tank for the rearing of water snails infected with bilharzia. A small child related to one of the staff dabbled its hand in the water on the morning before the parasites were introduced.

In each of these episodes some safety measures were subsequently introduced to prevent a recurrence. But retrospective, custom-built regulations are no way to prevent accidents entirely. We now have a situation where safety codes in a laboratory tend to be based on the past history of accidents in the establishment. Biohazard law would enable general safety measures to be introduced and enforced for the protection of all.

The literature of the past five years has included several examples where widespread hazards might have been involved. A form of infectious choriomeningitis reportedly caused five cases with three fatalities during experiments in the United States, and an unidentified virus from vervet monkeys has been stated to have caused over 30 cases with seven deaths despite the most rigorous attempts to contain the virus. Venezualan equine encephalitis is now said to be epizootic in Utah, having originated in biological warfare experiments.

Many hazards arise from the failure to maintain adequate supervision in laboratories. Junior or untrained staff may be given access to culture materials they do not understand. In some cases infected materials are disposed of by being poured down the same sink as 
The revealing lens, 19th century version. A William Heath etching of the 1820's depicts the contemporary view of microbiological hazards

that used for the preparation of tea and coffee.

There are interesting precedents in British law for the kind of proposals $Y$ envisage. The Factories Act 1961, Section 64, provides for the minister to extend the provisions banning eating in places where fumes or dangerous industrial dusts are produced; there is no mention of the far greater hazards that have biological origins (and, as the important case of Weston $v$ LCC (1941) showed, a technical institute is not a factory).

The conduct of workers in laboratories has an interesting precedent in the Agriculture (Poisonous Substances) Act 1952. Section 1 Subsection (c) calls for the "abstention from eating, drinking and smoking in circumstances involving the risk of poisoning" and Section 2 Subsection 1 (b) makes it a culpable offence to do anything to "wilfully cause risk of poisoning". Similar precautions with respect to microorganisms and viruses would not be hard to define.

The Radioactive Substances Acts, 1948 and 1960, define in detail the conditions under which radioactive substances should be handled, distributed, stored and controlled. The clear restriction of the availability of radioactive materials to "duly qualified medical practitioners or registered dental practitioners" is similar to what might be proposed for virulent pathogens. The Factories Act 1961 Section 18 Subsection (2) refers to the avoidance of dangers from "scalding, corrosive or poisonous" materials, to which list the infection risk could be appended. Section 82 of the same Act contains an anomalous, isolated reference to bacterial hazards when it refers to illnesses caused by lead, phosphorous, arsenic, mercury "and anthrax" as notifiable conditions, without reference to other infections of an occupational origin. The widespread use of microorganisms in industry, which an extention of biological engineering will inevitably entail, makes safeguards timely.

Conditions of storage have been covered in respect of phials containing vaccines, antibiotics and related biological products under Part III Section 5 (i) of the Therapeutic Substances Act 1956, which states that such containers must be sealed to "preclude the access of microorganisms" and later specifies the labelling of the outsides of the

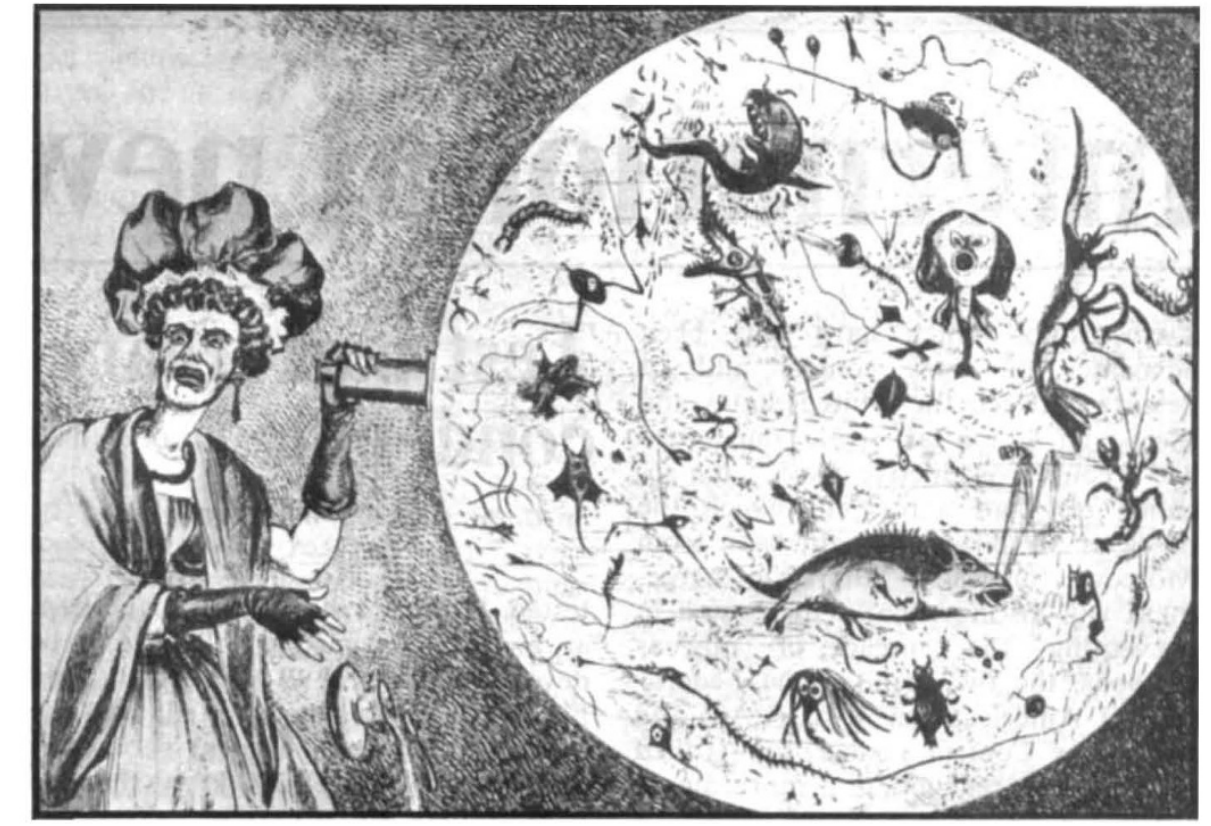

containers. A universal biohazard mark for glassware and other apparatus used to contain pathogens should be found. Perhaps a yellow spot or disk could be fused into glassware during manufacture as a permanent warning against the casual use of beakers or flasks for the preparation of refreshments. The recently introduced biohazard symbol displayed in some laboratories, or something like it modelled on the radiation sign, should be obligatory in all establishments handling pathogens.

Certain diseases are already notifiable, of course; though it is interesting that an organism in one's gall bladder may lead to restrictions by the health authorities which they would be powerless to impose if the organisms were carried, in a bottle, in one's trouser pocket instead. The only substantive reference to microorganisms occurs in the Therapeutic Substances Act Part II Section 4 (b) of 1956. It requires that separate laboratories be provided by licensees producing medical products if they "engage in the culture or manipulation of pathogenic spore-bearing microorganisms". It is already recognised by this Act that pathogenic contaminants must be kept out of containers of vaccines and the like, though the converse possibility-that organisms allowed to escape from within containers may pose even greater problems-is not referred to.

By far the greatest indictment of the current situation is the framework of controls within the Public Health Act 1936 and 1965; and the Health Services and Public Health Act 1968 (as amended by Schedule 14 and para 4 of Schedule 29 to the Local Government Act 1972).

These regulations contain a host of strictures on those unfortunate enough to contract smallpox, with limitations on the movement of people concerned and the use of library books and dustbins during an outbreak. The possibility that restrictions should be placed on the in vitro virus remains ignored.

Legislation should cover several specific areas:

- It should define groups of organisms, such as those of high pathogenicity (variola, tubercle, typhoid) which are not normally present in the environment but which pose problems to communities. These I have grouped as 'Schedule A' pathogens. The remainder, including streptococci and staphylococci, are widespread and should be subject to more basic safety regulations in the laboratory: these would constitute 'Schedule B' and would alone be available for school and teaching use.

- The status of licensed holders of Schedule A organisms and viruses would be defined in terms of academic training responsibility and seniority. Less severe restrictions would be placed on laboratories classified for the culture of Schedule B pathogens.

- Standards of safety in laboratories would be laid down and codes of conduct made mandatory. The registration of holders of specified pathogens would doubtless aid the coordination of the research effort, and clear sets of agreed criteria would apply to genetic manipulation of bacteria and viruses, and to the disposal of potentially hazardous materials.

It is indeed unfortunate that bacteria and viruses are still so widely seen as harmful. To many of them we owe our very existence. Yet they confer on the research worker considerable responsibility when he comes to work with pathogens en masse. A legal code is now overdue for academic, practical and humanitarian reasons. 